\title{
A atuação dos geógrafos na gestão ambiental: alternativas de solução para a contaminação por rejeitos sólidos a partir do rerrefino de óleo lubrificante
}

\section{The performance of geographers in environmental management: solution alternatives for contamination by solid waste from the refreshing of olive oil \\ El desempeño de los geógrafos en la gestión ambiental: Solución alternativas para la contaminación por residuos sólidos del refrescamiento del aceite lubrificante}

\begin{abstract}
Felipe César Augusto Silgueiro dos Santos - felipe.cesar@unesp.br Doutorando pelo Programa de Pós-Graduação em Geografia da Faculdade de Ciências e Tecnologia - Universidade Estadual Paulista (PPGG - FCT/UNESP) - Câmpus de Presidente Prudente/SP

ORCID: https://orcid.org/0000-0002-4073-0820
\end{abstract}

\begin{abstract}
Resumo
Este artigo é um estudo de caso da atividade dos geógrafos e das geógrafas com relação ao combate dos impactos ambientais causados pela empresa STARLUBRIFICANTES LTDA localizada em Presidente Prudente/SP e voltada ao rerrefino de óleo lubrificante. Tal atividade produz uma grande quantidade de dejetos, o que contamina o solo se não for destinado adequadamente. Assim é fundamental que o geógrafo e a geógrafa possam atuar de forma a mitigar os danos ocasionados por esta atividade industrial, não trazendo problemas ambientais e jurídicos para a empresa. Por esse estudo realizado, foi possível apresentar metodologias e procedimentos metodológicos que buscam facilitar o trabalho dos especialistas, com o intuito de contribuir para a dinâmica industrial e o meio ambiente. Ao final, faremos uma análise das atividades realizadas e quais foram os principais pontos de análise que ficam para a reflexão.
\end{abstract}

Palavras-chave: Geografia, Questão Ambiental, Ação Profissional, Presidente Prudente/SP.

\begin{abstract}
This article is a case study of the activity of geographers and geographers in relation to combating the environmental impacts caused by the company STARLUBRIFICANTES LTDA located in Presidente Prudente/SP and dedicated to the re-refining of lubricating oil. Such activity produces a large amount of waste, which contaminates the soil if not properly disposed of. Thus, it is essential that the geographer and the geographer can act to mitigate the damage caused by this industrial activity, not causing environmental and legal problems for the company. Through this study, it was possible to present methodologies and methodological procedures that seek to facilitate the work of specialists, in order to contribute to industrial dynamics and the environment. At the end, we will analyze the activities carried out and what were the main points of analysis that are left for reflection.
\end{abstract}

Key words: Geography, Environmental Issues, Professional Action, Presidente Prudente/SP. 


\section{Resumen}

Este artículo es un caso de estudio de la actividad de geógrafos y geógrafos en relación al combate a los impactos ambientales provocados por la empresa STARLUBRIFICANTES LTDA ubicada en Presidente Prudente / SP y dedicada al rerefinado de aceite lubricante. Tal actividad produce una gran cantidad de desechos que contaminan el suelo si no se eliminan adecuadamente. Por ello, es fundamental que el geógrafo y el geógrafo puedan actuar para mitigar los daños que ocasiona esta actividad industrial, no ocasionando problemas ambientales y legales a la empresa. A través de este estudio, fue posible presentar metodologías y procedimientos metodológicos que buscan facilitar el trabajo de los especialistas, con el fin de contribuir a la dinámica industrial y al medio ambiente. $\mathrm{Al}$ final, analizaremos las actividades realizadas y cuáles fueron los principales puntos de análisis que quedan para la reflexión.

Palabras-clave: Geografía, Asuntos Ambientales, Acción Profesional, Presidente Prudente / SP. 


\section{Introdução}

A atuação da geógrafa e do geógrafo no mercado de trabalho tem sido cada vez mais necessária por conta das grandes transformações que ocorrem, seja no meio urbano ou no rural. Compreender as dinâmicas do mundo atual e suas transformações se torna um desafio frente as grandes investidas capitalistas no meio social e ambiental.

Um exemplo que podemos utilizar é o papel do profissional geógrafo em dinâmicas industriais, que demandam um acompanhamento, pelo risco que representa. Temos como modelo a gestão ambiental do resíduo de óleos lubrificantes usados que possui elevado potencial de degradação ambiental, quando descartado incorretamente, mas, quando coletado e reciclado recupera suas características originais e pode retornar à cadeia produtiva por inúmeras vezes.

O processo de reciclagem de óleos lubrificantes, conhecido como rerrefino, representa uma interessante alternativa e vem sendo adotado por muitos países, inclusive no Brasil, com resultados positivos. Todavia, não são suficientes para solucionar o problema, sendo assim primordial a intervenção do setor público, por meio das políticas públicas e muitas resoluções para induzir o comportamento empresarial objetivando a preservação do ambiente.

Os impactos ambientais podem ser compreendidos a partir do entendimento de como as ações humanas influem nos processos ambientais, posto que o ser humano é o agente causador de degradação ambiental. Assim estes podem ser considerados como a alteração da qualidade ambiental provocada por ação humana (SANCHEZ, 2013).

Os impactos podem ser diretos, ou seja, aqueles originados nas fases de implantação e operação do empreendimento em sua área de influência direta, podendo desencadear ao longo do tempo impactos indiretos - já os indiretos são aqueles gerados a partir dos impactos diretos, tendo como origem o desenvolvimento do empreendimento ao longo do tempo em sua área de influência indireta.

Destarte, deve-se atentar para diferenciar poluição e impacto ambiental, uma vez que poluição tem conotação somente negativa e nem todo impacto ambiental tem a poluição como causa. Basicamente poluição é entendida como uma condição do entorno dos seres vivos (ar, água, solo) que lhes possam ser danosos e impacto ambiental é a interferência causada abruptamente no meio.

Pelo exposto, este artigo usará uma empresa de Presidente Prudente/SP, aqui nomeada de STARLUBRIFICANTES LTDA ${ }^{1}$ onde faremos uma investigação dos impactos ambientais causados pela mesma, visando que ela se enquadre nas delimitações exigidas pela Companhia Ambiental do Estado São Paulo (CETESB).

\section{Descrição do empreendimento e sua atividade industrial}

A STARLUBRIFICANTES LTDA foi implantada no município de Presidente Prudente - SP, região oeste do Estado de São Paulo, no dia 20/05/1983. A região da área de estudo insere-se no contexto geológico da porção

${ }^{1}$ Optamos por modificar o nome da empresa para um nome fantasia por preservar a mesma.

SANTOS, Felipe César Augusto Silgueiro dos. A atuação dos geógrafos na gestão ambiental: alternativas de solução para a contaminação por rejeitos sólidos a partir do rerrefino de óleo lubrificante. Boletim Alfenense de 
oeste do Estado de São Paulo, formado pelo conjunto representado pelas rochas sedimentares da Formação Adamantina, pertencente ao grupo Bauru (FERNANDES E SILVA, 2013).

Localizada na parte correspondente ao Distrito Industrial I (figura 01) da cidade de Presidente Prudente - SP, nas coordenadas geográficas latitude $22^{\circ} 09^{\prime}$ 35.82" e longitude $51^{\circ} 22$ ' 40,19”, SAD 69, Zona 22.

Figura o1 - Localização da área de pesquisa no perímetro urbano da cidade de Presidente Prudente/SP

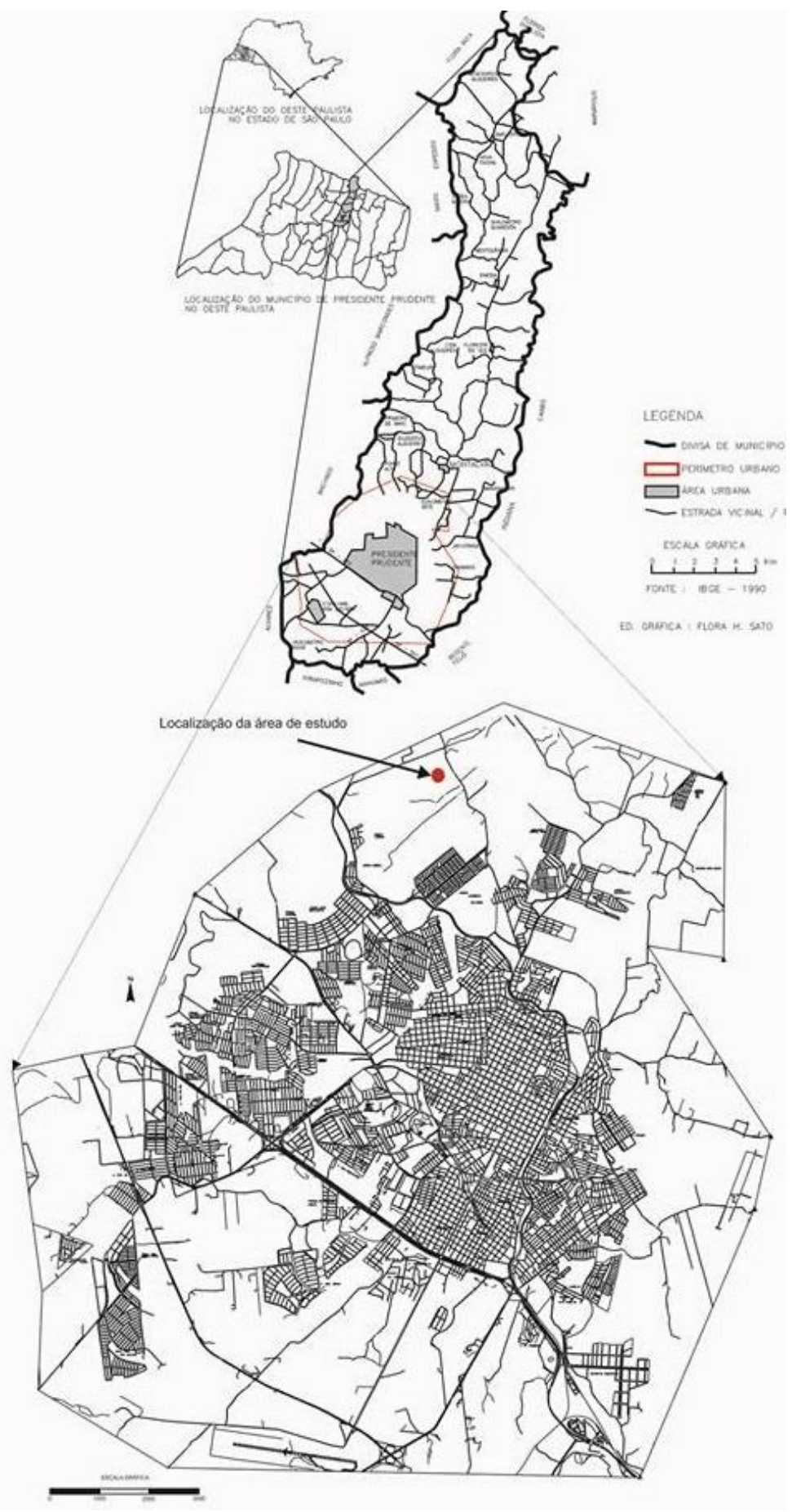

Fonte: FERNANDES e SILVA (2013).

SANTOS, Felipe César Augusto Silgueiro dos. A atuação dos geógrafos na gestão ambiental: alternativas de solução para a contaminação por rejeitos sólidos a partir do rerrefino de óleo lubrificante. Boletim Alfenense de Geografia. Alfenas. v. 1, n.2, p. 112-128, 2021. ISSN: 2764-1422. DOI: https://doi.org/10.29327/24.3949.1.2-9 
As áreas da empresa são vistoriadas pela CETESB há cerca de 30 anos, pois a rerrefinaria já foi notificada através de denúncias de terceiros, devido ao odor que a produção exala, principalmente para os visitantes de Presidente Prudente/SP, que reclamam do cheiro assim que chegam à cidade pela Rodovia Raposo Tavares.

A atividade industrial da empresa consiste na remoção de contaminantes, de produtos de degradação e aditivos de óleos lubrificantes usados ou contaminados, propiciando características de óleos básicos, em conformidade com as especificações técnicas da Agência Nacional de Petróleo -ANP, para a atividade de coleta rege a Resolução ANP $n^{0}$ 20, de 18/06/2009 - DOU 19/06/2009, para o rerrefino a Resolução ANP no 19, de 18/06/2009 - DOU 19/06/2009 e para ser produtor óleo lubrificante a Resolução ANP $\mathrm{n}^{0} 18$, de 18/06/2009 - DOU 19/06/2009, bem como, com Resolução CONAMA 362/05, a qual estabelece novas diretrizes para o recolhimento e destinação de óleo lubrificante usado ou contaminado.

A figura 03 apresenta basicamente um esquema do processo industrial de rerrefino de óleos lubrificantes:

Figura 03 - Processo Industrial do rerrefinos de óleos lubrificantes.

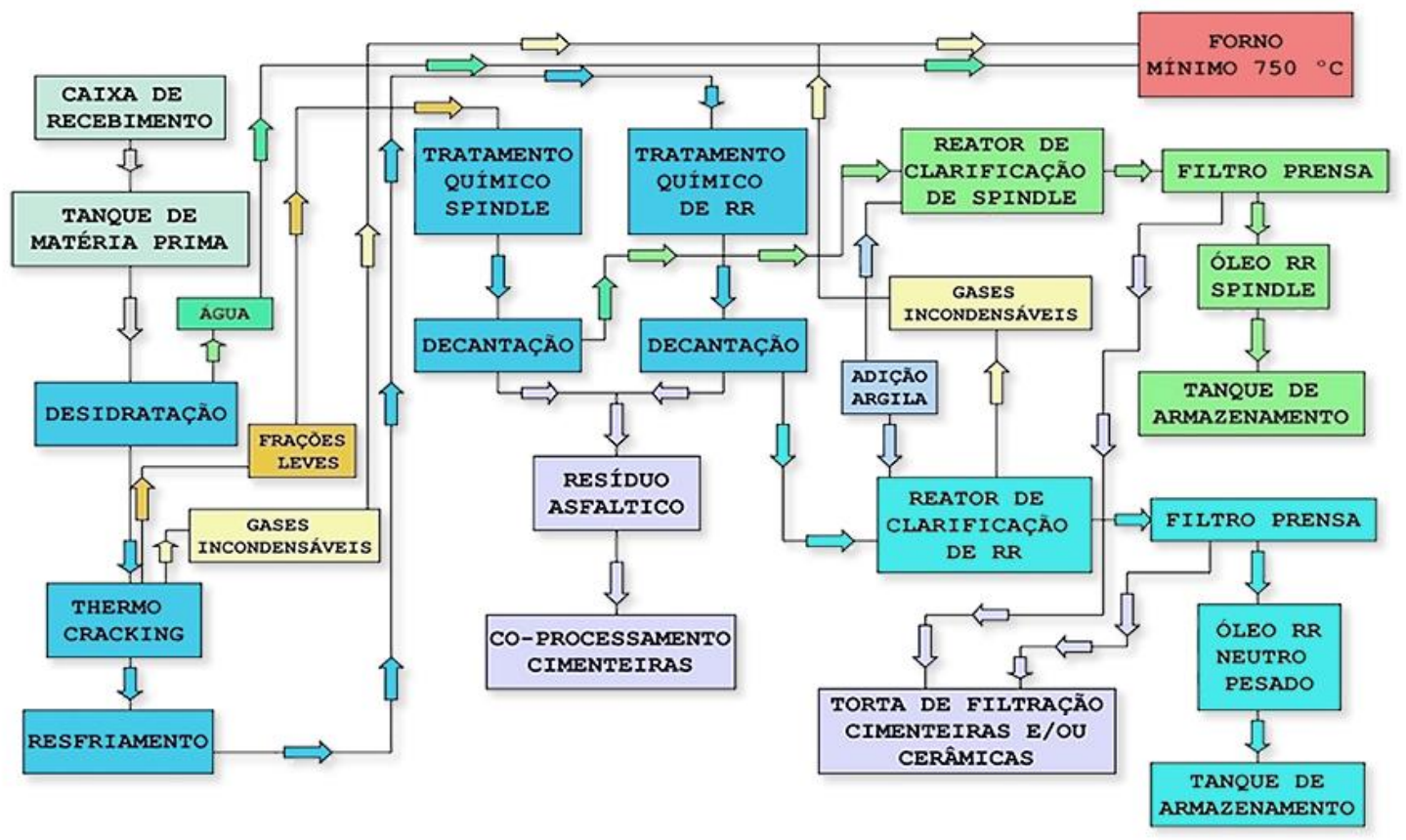

Fonte: SINDIRREFINO (2021)

Basicamente o processo é composto pela desidratação do óleo, visando limpar todo material que esteja ali depositado; posteriormente ocorre a destilação que será responsável pelo porcionamento do óleo tratado; após isso ocorre o desasfaltamento que visa fazer a limpeza das partes mais degradadas do óleo; depois é adicionado ácido sulfúrico que origina a "borra ácida" altamente poluente; depois ocorre a clarificação e a neutralização para que óleo fique mais puro possível e por fim a filtração, que passa por uma prensa para então ser armazenado nos tanques. 


\section{Diagnóstico ambiental}

O objetivo do Diagnóstico Ambiental é apresentar os principais elementos do meio natural e humano passíveis de modificações com a implantação e operação do empreendimento (SANCHEZ, 2013). Os dados utilizados foram obtidos através da CETESB sobre poluição do solo, água superficial e subterrânea, medição de níveis de ruídos, identificação de espécies vegetais e de fauna.

Sabe-se que há classificações para fontes de contaminação de solo e águas subterrâneas, ligadas à geração de substâncias, resíduos e/ou efluentes com potencial para contaminar o ambiente. Dentre elas estão: a contaminação por descarga no subsolo, o armazenamento no solo e a retenção de substâncias.

No local da STARLUBRIFICANTES LTDA é visível a contaminação do solo, o qual pode trazer diversas consequências para o ambiente ou até mesmo se tornar um problema de saúde pública, visto que o aquecimento da borra ácida pelo calor do sol propicia o odor característico, enquanto que a precipitação a faz escoar até as áreas de planícies, isto é, até o curso d’água mais próximo.

A figura 4 traz uma representação do que seria a contaminação do solo por borra ácida, exposta ao calor e que dissipa um odor forte:

Figura 4 - Solo contaminado por borra ácida de óleo diesel

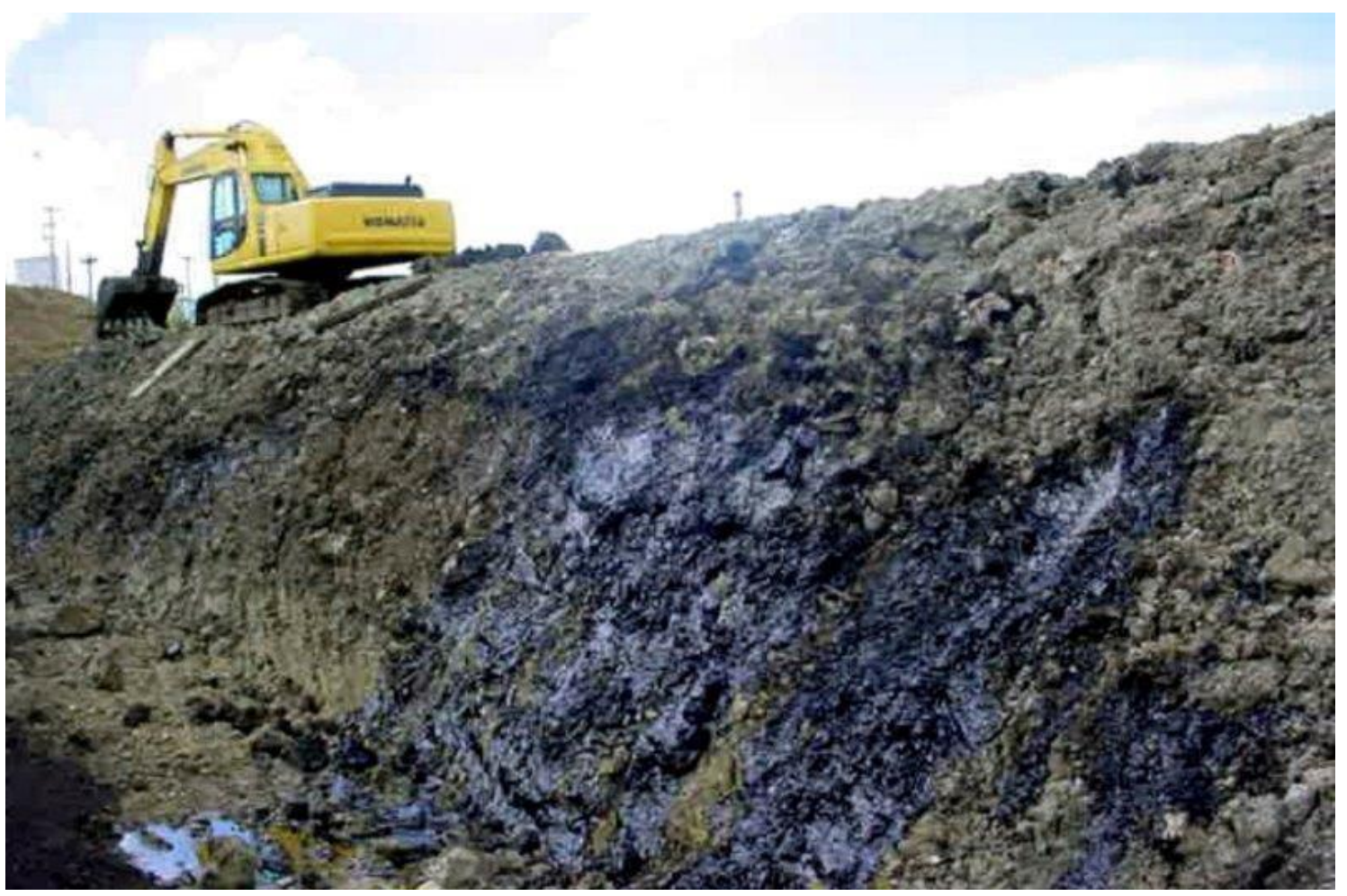

Fonte: TSL Ambiental (2021)

Das consequências, a contaminação de aquíferos (abastecimento de água para a população) é outra importante alteração, porque grande parte da borra ácida depositada no solo, escoa superficialmente, devido à pluviosidade e infiltra, contudo, não é o suficiente para atingir as águas subterrâneas da área de localização da empresa, graças ao fato de que o solo ser um agente filtrante.

SANTOS, Felipe César Augusto Silgueiro dos. A atuação dos geógrafos na gestão ambiental: alternativas de solução para a contaminação por rejeitos sólidos a partir do rerrefino de óleo lubrificante. Boletim Alfenense de Geografia. Alfenas. v. 1, n.2, p. 112-128, 2021. ISSN: 2764-1422. DOI: https://doi.org/10.29327/243949.1.2-9 
Mesmo assim, apesar da baixa concentração de certas substâncias químicas, ainda ocorre o acúmulo de contaminantes no solo, ocasionando alteração na qualidade.

O empreendimento pode gerar diversos impactos ambientais em diferentes escalas. Ou seja, desde a sua pré-implantação pode-se identificar o transporte e a circulação de caminhões pesados, para a preparação dos acessos ao empreendimento, em seguida, a supressão de vegetação, escavação e terraplanagem, isto é, as obras em si, durante seu funcionamento o destino dos resíduos e poluentes ocasionados no processo industrial. Através da análise da matriz abaixo podemos verificar que o maior impacto será na qualidade do solo, conforme a identificação dos impactos pré-avaliada na Matriz de Leopold:

Quadro 1 - Matriz de identificação de impactos potenciais da STARLUBRIFICANTES LTDA

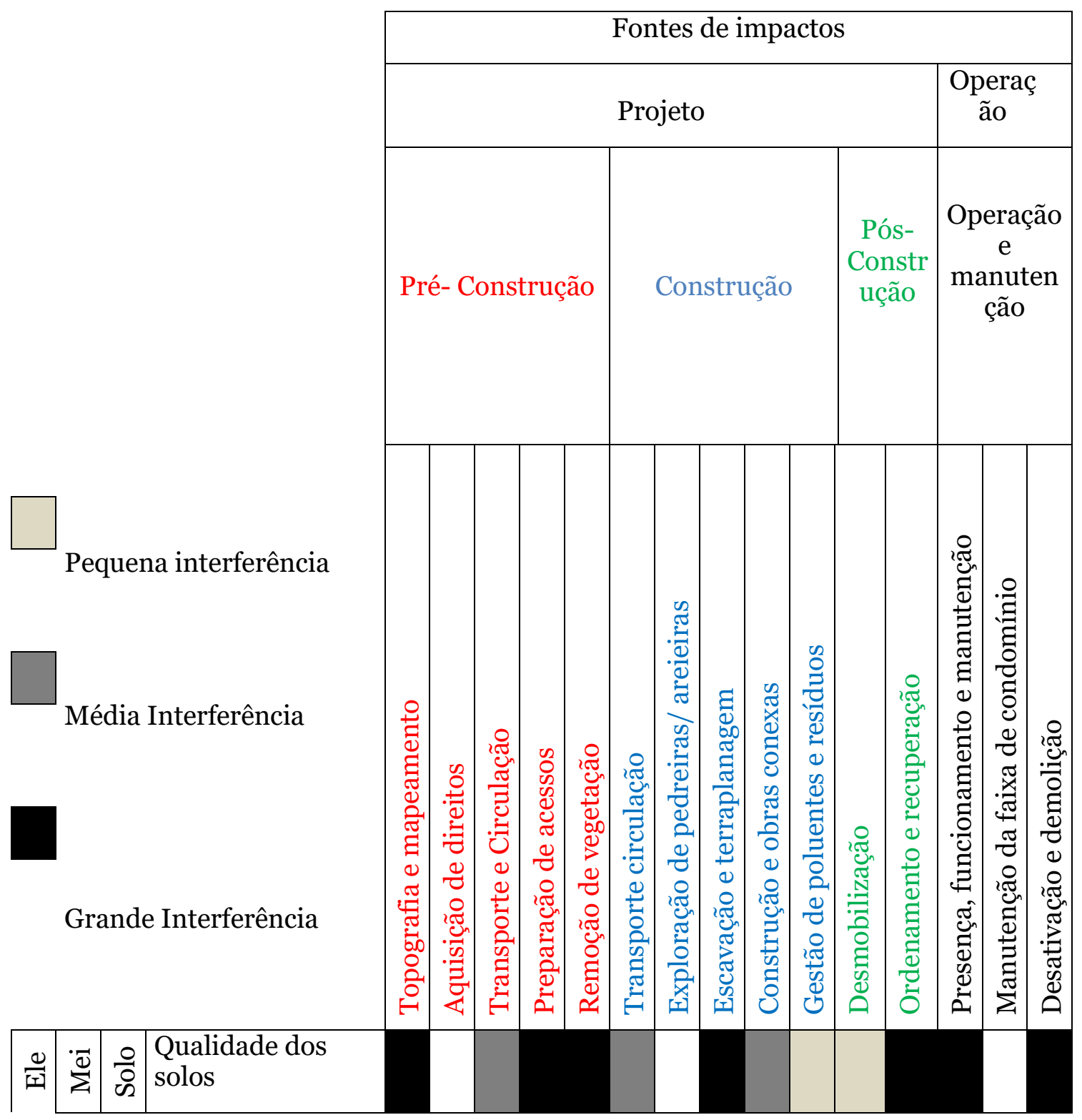

SANTOS, Felipe César Augusto Silgueiro dos. A atuação dos geógrafos na gestão ambiental: alternativas de solução para a contaminação por rejeitos sólidos a partir do rerrefino de óleo lubrificante. Boletim Alfenense de Geografia. Alfenas. v. 1, n.2, p. 112-128, 2021. ISSN: 2764-1422. DOI: https://doi.org/10.29327/243949.1.2-9 


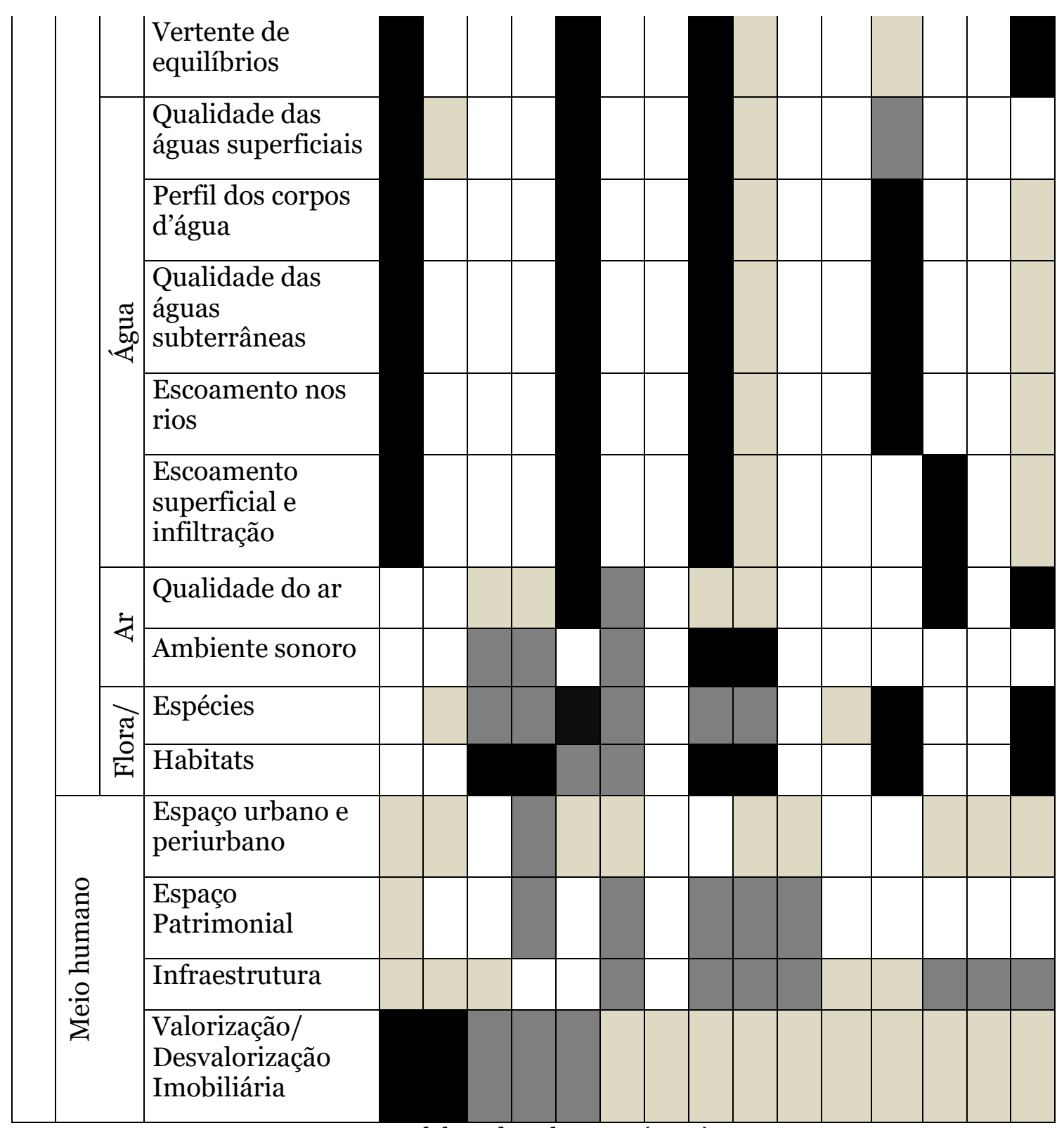

Fonte: Elaborado pelo autor (2021)

A Matriz de Leopold possui a função de estabelecer critérios numéricos com relação a dimensão da potencialidade de determinado impacto, mensurando sua capacidade de afetação ou não. Destaca-se por possuir duas frentes divergentes de análise: a valoração de magnitude que é muito mais objetiva, já que visa trazer o grau de alteração do impacto e a pontuação da importância, que é mais subjetiva, já que envolve um valor relativo (CAVALCANTI; LEITE, 2016).

Os impactos ambientais em relação ao tempo em que podem ocorrer, são classificados em imediato, médio prazo, temporário, reversível e irreversível. Sabemos que com o passar do tempo o impacto pode afetar a perda da qualidade ambiental, ou seja, na área estudada observamos a degradação da vegetação com a exposição do solo.

Com relação à degradação do ambiente podemos avaliar a combinação de atributos, no caso utilizaremos os atributos magnitude, reversibilidade e extensão, os quais podem ser combinados resultando em arranjos, como impacto reversível de pequena magnitude e extensão. Podemos citar a deterioração da 
qualidade do ar, pois o impacto é local e pode ser revertido com a utilização de filtros de ar.

Quanto aos impactos irreversíveis de pequena magnitude podemos citar a deterioração da qualidade das águas subterrâneas, que podem ter extensão variável. Já os impactos irreversíveis de média e grande magnitude não foram identificados. Segue quadro abaixo:

Quadro o2 - Combinação de atributos e respectivos impactos ambientais

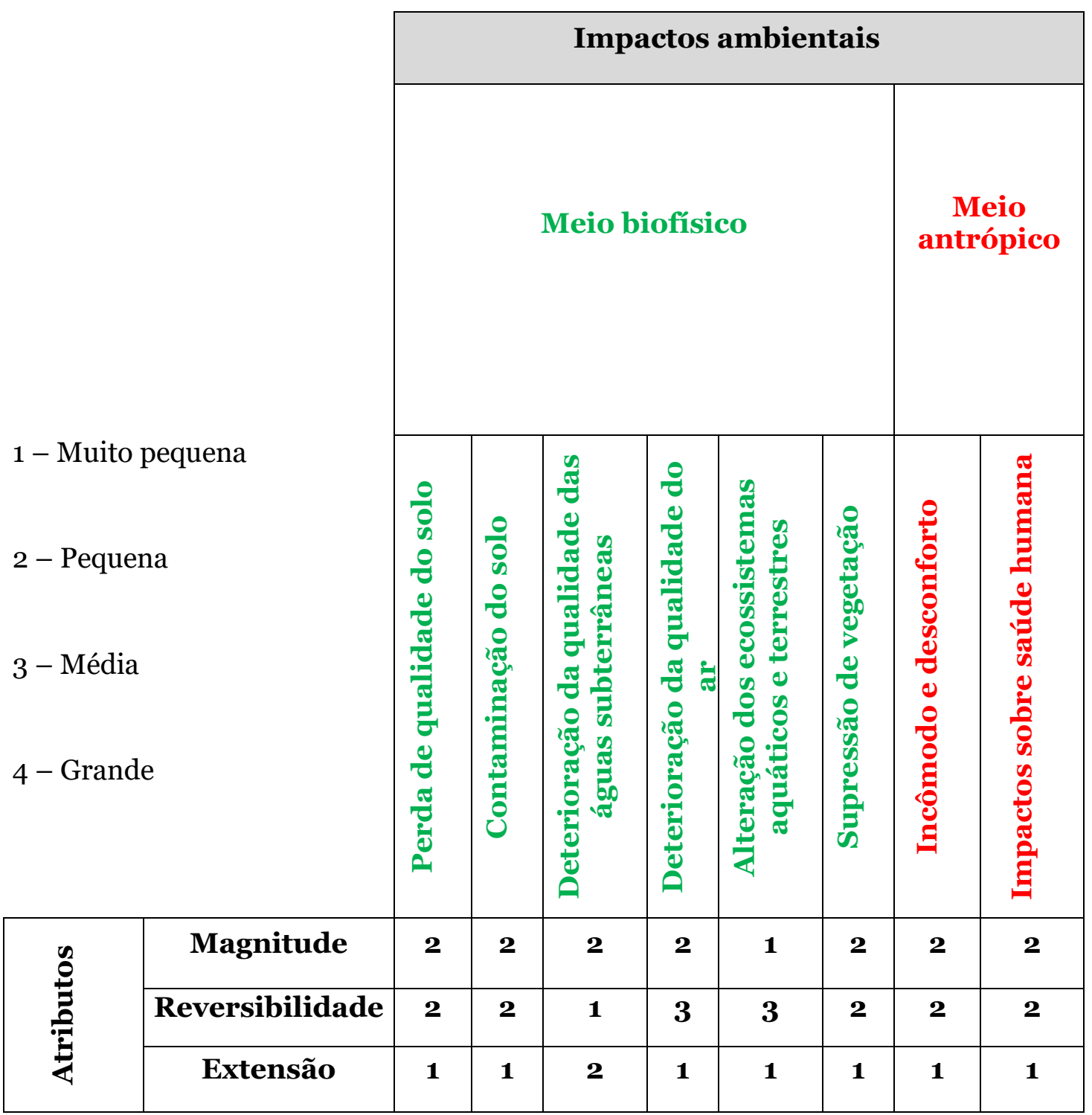

Fonte: Elaborado pelo autor (2021)

Para facilitar uma classificação do grau de importância dos impactos ambientais em questão, definiremos como critério de avaliação três atributos: duração, extensão e magnitude (ou intensidade). Quanto ao atributo duração, este será classificado como: momentâneo, temporário ou permanente. Já o atributo extensão poderá ser: pontual, local, regional, e por último a magnitude será classificada por adjetivos que denotem intensidade: fraca, média, forte ou 
muito forte. Nessa classificação os impactos de grande importância são aqueles que tenham maior intensidade ou magnitude, como segue no quadro:

Quadro o3 - Classificação do grau de importância de impactos ambientais

\begin{tabular}{|c|l|l|l|l|l|l|}
\hline \multirow{2}{*}{$\begin{array}{c}\text { Impacto } \\
\text { Puração }\end{array}$} & Extensão & \multicolumn{3}{|c|}{ Magnitude ou intensidade } \\
\cline { 4 - 7 } & Fraca & Média & Forte & $\begin{array}{c}\text { Muito } \\
\text { forte }\end{array}$ \\
\hline $\begin{array}{c}\text { Perda da } \\
\text { sualo }\end{array}$ & Permanente & Pontual & Grande & Média & Pequena & Pequena \\
\hline $\begin{array}{c}\text { Contaminação } \\
\text { do solo }\end{array}$ & Permanente & Pontual & Grande & Média & Pequena & Pequena \\
\hline $\begin{array}{c}\text { Deterioração } \\
\text { da qualidade } \\
\text { das águas } \\
\text { subterrâneas }\end{array}$ & Temporária & Pontual & Média & Pequena & Pequena & Pequena \\
\hline $\begin{array}{c}\text { Deterioração } \\
\text { da qualidade } \\
\text { do ar }\end{array}$ & Temporária & Local & Pequena & Pequena & Pequena & Pequena \\
\hline $\begin{array}{c}\text { Alteração dos } \\
\text { ecossistemas } \\
\text { aquáticos e } \\
\text { terrestres }\end{array}$ & Temporária & Pontual & Pequena & Pequena & Pequena & Pequena \\
\hline $\begin{array}{c}\text { Supressão de } \\
\text { vegetação }\end{array}$ & Permanente & Pontual & Pequena & Pequena & Pequena & Pequena \\
\hline $\begin{array}{c}\text { Incômodo e } \\
\text { desconforto }\end{array}$ & Temporária & Local & Média & Pequena & Pequena & Pequena \\
\hline $\begin{array}{c}\text { Impactos } \\
\text { sobre saúde } \\
\text { humana }\end{array}$ & Permanente & Local & Média & Pequena & Pequena & Pequena \\
\hline
\end{tabular}

Fonte: Elaborado pelo autor (2021)

\section{Avaliação de riscos}

A avaliação dos riscos é uma ferramenta importante para reconhecer os perigos e "gerenciar a crise", ou seja, reduzir a chance de impactos ambientais que possam vir a ocorrer, mas antes de haver a falha em si. Assim, risco, como definido pela Society for Rick Analysis, é o potencial de ocorrência de resultados adversos indesejados para a saúde ou vida humana, para o ambiente ou para bens materiais. Risco pode ser definido de modo mais formal como o produto da probabilidade de ocorrência de um determinado evento pela magnitude das consequências, ou $\mathrm{R}=\mathrm{P}$ x C. Utilizando-se essa expressão, é possível calcular matematicamente diversos riscos e comparar diferentes situações de risco. (SANCHEZ, 2013) 
Deve-se atentar para os riscos de maneira a refletir sobre o inimaginável, como mal funcionamento de máquinas modernas e/ou automáticas, quantidade de despejos irregular, acidentes envolvendo funcionários, visto que o risco é um tipo de impacto ambiental.

Existem muitas classificações para os chamados "riscos ambientais", eles podem ser classificados como naturais (atmosféricos, hidrológicos, geológicos, biológicos e siderais), tecnológicos (agudos e crônicos) e os riscos à saúde (humana ou dos ecossistemas) (SANCHEZ, 2013). As atividades de risco são chamadas de perigosas, e incluem, dentre aquelas capazes de causar dano ambiental, muitas atividades industriais, o transporte e o armazenamento de produtos químicos, o lançamento de poluentes ou a manipulação genética. Essas situações podem acarretar danos materiais, danos aos ecossistemas ou danos à saúde do homem - e não raro ocorrem os três tipos de danos. (SANCHEZ, 2013)

Dentre os riscos analisaremos os tecnológicos, considerando que o empreendimento analisado deposita a borra no solo a céu aberto, caso ocorra uma incidência solar demasiadamente elevada, pode haver a combustão espontânea, face a quantidade óleo (borra) que fica infiltrada sobre o substrato terrestre, sendo este inflamável, pode haver a liberação de calor fazendo com que evapore e entre em combustão espontânea. descrita:

O quadro 04 identifica a avaliação preliminar de perigos (APP) acima

Quadro 04 - Análise Preliminar de Perigos - APP

\begin{tabular}{|c|c|c|c|c|c|c|c|}
\hline \multicolumn{8}{|c|}{ Análise Preliminar de Perigos (APP) } \\
\hline Perigo & Causa & $\begin{array}{c}\text { Modo } \\
\text { de } \\
\text { detecȩ } \\
\text { ão }\end{array}$ & Efeito & $\begin{array}{c}\text { Catego } \\
\text { ria de } \\
\text { Frequ } \\
\text { ência }\end{array}$ & $\begin{array}{c}\text { Catego } \\
\text { ria de } \\
\text { Severi } \\
\text { dade }\end{array}$ & $\begin{array}{c}\text { Categ } \\
\text { oria } \\
\text { de } \\
\text { Risco }\end{array}$ & $\begin{array}{c}\text { Observ } \\
\text { ações }\end{array}$ \\
\hline $\begin{array}{c}\text { Eventos } \\
\text { que } \\
\text { podem } \\
\text { ter } \\
\text { consequ } \\
\text { ências } \\
\text { ambient } \\
\text { ais ou } \\
\text { para a } \\
\text { saúde ou } \\
\text { seguranç } \\
\text { a } \\
\text { humana }\end{array}$ & $\begin{array}{c}\text { Falhas } \\
\text { intrínse } \\
\text { cas de } \\
\text { equipam } \\
\text { entos e } \\
\text { erros } \\
\text { humano } \\
\text { s de } \\
\text { manute } \\
\text { nção ou } \\
\text { operaçã } \\
\text { o }\end{array}$ & $\begin{array}{c}\text { Instru } \\
\text { mento } \\
\text { ou } \\
\text { percepç } \\
\text { ão } \\
\text { human } \\
\text { a }\end{array}$ & $\begin{array}{c}\text { Comporta } \\
\text { mento de } \\
\text { um } \\
\text { produto } \\
\text { liberado } \\
\text { ou } \\
\text { consequê } \\
\text { ncia } \\
\text { imediata } \\
\text { do evento }\end{array}$ & $\begin{array}{l}\text { Classifi } \\
\text { cação } \\
\text { de } \\
\text { acordo } \\
\text { com } \\
\text { categori } \\
\text { as } \\
\text { definid } \\
\text { as } \\
\text { previa } \\
\text { mente, } \\
\text { como } \\
\text { “muito } \\
\text { prováve } \\
\text { l”, } \\
\text { “prováv } \\
\text { el”, } \\
\text { “ocasio } \\
\text { nal” etc. }\end{array}$ & $\begin{array}{c}\text { Classific } \\
\text { ação de } \\
\text { acordo } \\
\text { com } \\
\text { categori } \\
\text { as } \\
\text { definida } \\
\text { s } \\
\text { previam } \\
\text { ente, } \\
\text { como } \\
\text { “catastr } \\
\text { ófico", } \\
\text { “desprez } \\
\text { ível” etc. }\end{array}$ & $\begin{array}{c}\text { Combi } \\
\text { nação } \\
\text { de } \\
\text { severid } \\
\text { ade e } \\
\text { frequê } \\
\text { ncia, de } \\
\text { acordo } \\
\text { com } \\
\text { critério } \\
\text { pré- } \\
\text { definid } \\
\text { o }\end{array}$ & $\begin{array}{l}\text { Informa } \\
\text { ção } \\
\text { comple } \\
\text { mentar } \\
\text { ou } \\
\text { recomen } \\
\text { dação de } \\
\text { ações } \\
\text { preventi } \\
\text { vas }\end{array}$ \\
\hline
\end{tabular}

SANTOS, Felipe César Augusto Silgueiro dos. A atuação dos geógrafos na gestão ambiental: alternativas de solução para a contaminação por rejeitos sólidos a partir do rerrefino de óleo lubrificante. Boletim Alfenense de Geografia. Alfenas. v. 1, n.2, p. 112-128, 2021. ISSN: 2764-1422. DOI: https://doi.org/10.29327/243949.1.2-9 


\begin{tabular}{|c|c|c|c|c|c|c|c|}
\hline \multicolumn{8}{|c|}{ 1-) Armazenamento da borra ácida a céu aberto } \\
\hline $\begin{array}{c}\text { Infilttraç } \\
\text { ão, } \\
\text { evaporaç } \\
\text { ão e } \\
\text { combust } \\
\text { ão }\end{array}$ & $\begin{array}{c}\text { Combus } \\
\text { tão } \\
\text { espontâ } \\
\text { nea } \\
\text { quando } \\
\text { exposto } \\
\text { à } \\
\text { tempera } \\
\text { tura } \\
\text { ambient } \\
\text { e }\end{array}$ & Visual & $\begin{array}{c}\text { Liberação } \\
\text { de calor } \\
\text { ou chama }\end{array}$ & Raro & Pequena & $\begin{array}{l}\text { Muito } \\
\text { Baixo }\end{array}$ & $\begin{array}{l}\text { Inspeção } \\
\text { Periódic } \\
\text { a das } \\
\text { pilhas } \\
\text { treiname } \\
\text { nto de } \\
\text { operado } \\
\text { res para } \\
\text { extinção } \\
\text { de focos }\end{array}$ \\
\hline \multicolumn{8}{|c|}{ 2-) Bolhas formadas pelo óleo fluido (pressão na tubulação) } \\
\hline $\begin{array}{c}\text { Pequeno } \\
\text { s } \\
\text { vazamen } \\
\text { tos }\end{array}$ & $\begin{array}{c}\text { Furos } \\
\text { ou } \\
\text { rupturas } \\
\text { na } \\
\text { tubulaçã } \\
\text { o e } \\
\text { tanques, } \\
\text { vazame } \\
\text { ntos em } \\
\text { válvulas } \\
\text { ou } \\
\text { conexõe } \\
\text { s }\end{array}$ & Visual & $\begin{array}{l}\text { Liberação } \\
\text { para piso, } \\
\text { ou, } \\
\text { atingir } \\
\text { funcionár } \\
\text { ios. }\end{array}$ & Raro & $\begin{array}{c}\text { Modera } \\
\text { da }\end{array}$ & Baixo & $\begin{array}{l}\text { Inspeção } \\
\text { Periódic } \\
\text { a e } \\
\text { manuten } \\
\text { ção } \\
\text { preventi } \\
\text { va. }\end{array}$ \\
\hline
\end{tabular}

\section{Plano de gestão ambiental}

O plano de gestão geralmente apresenta medidas mitigadoras, que ao serem executadas visam reduzir os impactos negativos de um empreendimento. $\mathrm{Na}$ prática a finalidade é constatar, com a ajuda de todos os indicadores analisados anteriormente se o empreendimento funciona de acordo com as especificações estabelecidas legalmente, no intuito de obter o licenciamento ambiental para que o empreendedor esteja em conformidade com as condições impostas pelo agente regulador e evite receber autuações e multas.

As áreas contaminadas da STARLUBRIFICANTES LTDA são vistoriadas pela CETESB há cerca de 30 anos, pois a rerrefinaria já foi notificada através de denúncias de terceiros, devido ao odor que a produção exala, o que poderia ser amenizado com a instalação de um limpador de gases, posto que a queima de óleo usado sem um pré-tratamento pode lançar na atmosfera compostos clorados e sulfurados, monóxido de carbono, dioxinas, metais pesados (chumbo, cromo, cádmio, zinco) e vários tipos de substâncias tóxicas e corrosivas, algumas com ação cancerígena.

A instalação de poços de monitoramento de água subterrânea para controle da qualidade poderá também ser implantado, isto porque apenas 5 litros de óleo usado podem recobrir uma superfície de $5.000 \mathrm{~m}^{2}$ de lago, matando seus organismos pela asfixia. Ressaltamos que a localização da indústria é próxima a 
um lixão de Presidente Prudente/SP, o que pode culminar em um problema ambiental de grande magnitude.

A empresa deverá destinar recursos financeiros para capacitar um grupo de funcionários voltados para a conscientização ambiental, assim como, buscar aprimoramento dos processos, estabelecendo novos patamares de responsabilidades, reaproveitamento e redução no consumo de matérias primas e energia, com consequências fundamentais para o custo da STARLUBRIFICANTES LTDA, bem como, minimizar o número de acidentes de trabalho.

Por fim, utilizando-se de todas as medidas mencionadas e também as elencadas nos quadros abaixo (Quadro o5 e 06), a empresa mostrará que vem tomando medidas que a caracterizam como uma empresa pró-ativa e que servirá de exemplo para as demais empresas do mesmo ramo de atividade:

Quadro 05 - Quadro sintético descritivo de um plano de gestão ambiental

\begin{tabular}{|c|c|c|}
\hline Impacto & Ação Proposta & Tipo \\
\hline Poluição do solo & $\begin{array}{l}\text { Reduzir o despejo da borra } \\
\text { ácida diretamente no solo }\end{array}$ & $\mathrm{M}$ \\
\hline $\begin{array}{l}\text { Poluição das águas } \\
\text { subterrâneas }\end{array}$ & $\begin{array}{l}\text { Identificação das bacias } \\
\text { para preservação }\end{array}$ & $\mathrm{M}$ \\
\hline Poluição do ar & Instalação de filtros de ar & $\mathrm{E}$ \\
\hline Poluição sonora & $\begin{array}{l}\text { Isolar a casa de máquinas e } \\
\text { regular escapamento e } \\
\text { motores dos veículos da } \\
\text { empresa }\end{array}$ & $\mathrm{E}$ \\
\hline Supressão da vegetação & $\begin{array}{l}\text { Minimizar a supressão e } \\
\text { efetuar o reflorestamento } \\
\text { da área afetada }\end{array}$ & $\mathrm{C}$ \\
\hline $\begin{array}{l}\text { Valorização/ } \\
\text { Desvalorização imobiliária }\end{array}$ & $\begin{array}{l}\text { Mobilização dos } \\
\text { moradores para exigir } \\
\text { cumprimento da lei } \\
\text { ambiental }\end{array}$ & $\mathrm{M}$ \\
\hline \multicolumn{3}{|c|}{ M-Medidas de mitigação ou atenuação de impactos negativos. } \\
\hline \multicolumn{3}{|c|}{ C-Medidas de compensação de impactos negativos. } \\
\hline \multicolumn{3}{|c|}{$V$ - Medidas de valorização de impactos positivos. } \\
\hline \multicolumn{3}{|l|}{ E-Estudos complementares. } \\
\hline \multicolumn{3}{|c|}{ G-Medidas de capacitação e gestão. } \\
\hline
\end{tabular}


Quadro o6 - Quadro de síntese de programas ambientais

\begin{tabular}{|c|c|}
\hline Título & Programa de Redução de Poluição do solo \\
\hline Objetivo & Reduzir o despejo da borra ácida diretamente no solo \\
\hline Resultados esperados & $\begin{array}{l}\text { Reverter a contaminação do solo } \\
\text { Reduzir a infiltração de substâncias químicas no solo }\end{array}$ \\
\hline Conteúdo resumido & $\begin{array}{l}\text { Vedação do tanque de despejo de borra ácida com material } \\
\text { plástico próprio impermeabilizante } \\
\text { Utilização de serragem para absorção mesmo que parcial } \\
\text { da borra acumulada } \\
\text { Transporte dos rejeitos (serragem) para local mais } \\
\text { adequado e sua correta incineração }\end{array}$ \\
\hline $\begin{array}{l}\text { Indicadores para } \\
\text { avaliação dos } \\
\text { resultados }\end{array}$ & $\begin{array}{l}\text { Visualização do aspecto do solo } \\
\text { Testes laboratoriais de análise da qualidade do solo }\end{array}$ \\
\hline Cronograma & Todo o período de redução \\
\hline Responsáveis & Supervisor ambiental \\
\hline Título & $\begin{array}{l}\text { Programa de Redução de Poluição das águas } \\
\text { subterrâneas }\end{array}$ \\
\hline Objetivo & $\begin{array}{l}\text { Reduzir o escoamento superficial e a infiltração de } \\
\text { substâncias químicas resultantes do processo industrial }\end{array}$ \\
\hline Resultados esperados & $\begin{array}{l}\text { Evitar a infiltração substâncias químicas resultantes do } \\
\text { processo industrial, que podem atingir os cursos d'água e o } \\
\text { aquífero freático }\end{array}$ \\
\hline Conteúdo resumido & $\begin{array}{l}\text { Vedação do tanque de despejo de borra ácida com material } \\
\text { plástico próprio impermeabilizante utilizando serragem } \\
\text { para absorção do mesmo. } \\
\text { Transporte dos rejeitos (serragem) para local mais } \\
\text { adequado e sua correta incineração }\end{array}$ \\
\hline $\begin{array}{l}\text { Indicadores para } \\
\text { avaliação dos } \\
\text { resultados }\end{array}$ & $\begin{array}{l}\text { Testes laboratoriais de análise da qualidade das águas } \\
\text { subterrâneas e de cursos d'água próximo ao local }\end{array}$ \\
\hline Cronograma & Todo o período de redução \\
\hline Responsáveis & Supervisor ambiental \\
\hline Título & Programa de Redução de Poluição do ar \\
\hline Objetivo & $\begin{array}{l}\text { Reduzir o odor característico do processo de rerrefino de } \\
\text { óleos lubrificantes usados }\end{array}$ \\
\hline Resultados esperados & $\begin{array}{l}\text { Minimizar o odor característico } \\
\text { Aumentar a qualidade da saúde das pessoas afetadas pelo } \\
\text { odor }\end{array}$ \\
\hline Conteúdo resumido & $\begin{array}{l}\text { Instalação de filtros específicos para esse ramo de atividade } \\
\text { Supervisão dos moradores de bairro entorno da empresa }\end{array}$ \\
\hline $\begin{array}{l}\text { Indicadores para } \\
\text { avaliação dos } \\
\text { resultados }\end{array}$ & Equipamento de controle de emissão de gases poluentes \\
\hline Cronograma & Todo o período de redução \\
\hline Responsáveis & Supervisor ambiental \\
\hline Título & Programa de Redução de Poluição sonora \\
\hline Objetivo & Reduzir a emissão de poluição sonora \\
\hline
\end{tabular}




\begin{tabular}{|l|l|}
\hline Resultados esperados & $\begin{array}{l}\text { Aumentar a qualidade da saúde das pessoas afetadas pelo } \\
\text { som }\end{array}$ \\
\hline Conteúdo resumido & $\begin{array}{l}\text { Isolar com a devida acústica a casa de máquinas da } \\
\text { indústria } \\
\text { Regular escapamentos e motores dos veículos da empresa }\end{array}$ \\
\hline $\begin{array}{l}\text { Indicadores para } \\
\text { avaliação dos } \\
\text { resultados }\end{array}$ & $\begin{array}{l}\text { Quando os funcionários puderem deixar de utilizar } \\
\text { abafadores auriculares será um bom sinal de redução de } \\
\text { sons }\end{array}$ \\
\hline Cronograma & Todo o período de redução \\
\hline Responsáveis & \multicolumn{1}{|c|}{ Técnico de produção } \\
\hline Título Gerente
\end{tabular}

Fonte: Elaborado pelo autor (2021).

\section{Considerações Finais}

A profissão do geógrafo e da geógrafa ganha cada vez mais importância pela qualidade técnica de suas atividades, que permitem uma observação apurada das dinâmicas ocorrentes, sejam no meio urbano ou rural. É fundamental ter em mente que questões ambientais de grande risco possuem a capacidade de serem mitigadas pela dedicação dos profissionais e seu conhecimento em gestão ambiental.

Com a dinamização industrial, o meio natural ecológico foi sendo cada vez mais apossado pelos detentores do capital, que se utilizam de seus recursos financeiros para expandir suas atividades industriais. Tal fato denota a importância de compreender como esses processos antrópicos afetarão o meio 
ambiente, já que cada vez mais ele é afetado pelas inúmeras alterações, seja no solo, no ecossistema, aquíferos e etc. (SUERTEGARAY; SCHAFFER, 1986).

Este ponto pode ser observado ao analisarmos as atividades da empresa STARLUBRIFICANTES LTDA, que possui atuação há mais de 30 anos na cidade de Presidente Prudente/SP e apresenta inúmeras problemáticas ambientais que demandam uma atenção das autoridades.

Tal realidade segue apenas o modelo econômico capitalista, que busca a produção e readequação dos materiais, por conta da necessidade de se produzir e de manter um padrão econômico pautado no lucro (SANTOS, 1986). Logo é fundamental reconhecer e analisar quais os problemas causados por atividades como as descritas acima, visando a preservação do meio ambiente e como forma de combater os excessos produzidos pelo capitalismo.

Destacamos também que é fundamental que o geógrafo e a geógrafa que forem responsáveis por essas análises técnicas, se apropriem adequadamente das metodologias e das ferramentas disponíveis, buscando utilizá-las corretamente, com o intuito até mesmo de prever possíveis desastres ecológicos que possam ocorrer por conta da má gestão das atividades industriais em meio ambientais (AB'SABER, 2007).

Portanto, é fundamental continuarmos estimulando essas atividades dos profissionais geógrafos e geógrafas, com o intuito de buscar a preservação do meio ambiente e do uso adequado das ferramentas disponíveis, possibilitando inclusive o estímulo para que essas sejam ensinadas e repassadas para outros profissionais de outras áreas.

\section{Referências}

AB'SABER, Aziz Nacib. Uma ética para a vida. In:

O que é ser geógrafo: Memórias profissionais de Aziz Ab'Saber em depoimento a Cynara Menezes. Rio de Janeiro: Record, 2007, p. 145 - 155)

CAVALCANTI, Leonardo Gondim, LEITE, Adriana de Oliveira Sousa. Aplicação da Matriz de Leopold com ferramenta de avaliação dos aspectos e impactos ambientais em uma fábrica de botijões. Revista Tecnologia, v. 37, n. 1/2, p. 114, 2016.

PHILIPPI Jr., Arlindo; ROMÉRO, Marcelo de Andrade e BRUNA, Gilda Collet. Curso de Gestão Ambiental. Barueri: Editora Manole. 2011.

SANCHEZ, Luís Henrique. Avaliação de Impacto Ambiental. São Paulo: Oficina de Textos, 2013.

SANTOS, Milton. As dificuldades do método. In: O trabalho do geógrafo no Terceiro Mundo. São Paulo: Editora Hucitec, 1986, p. 7 - 33 
SUERTEGARAY, Dirce Maria Antunes; SCHAFFER, Neiva Otero. Análise ambiental: A atuação do Geógrafo para e na sociedade. Revista Terra Livre, v. O3, p. 1 - 15, 1988.

SILVA, Ana Cláudia; FERNANDES, Camila Rodrigues. Análise de contaminação do solo e água subterrânea em área utilizada para descarte de rejeitos provenientes do rerrefino de óleo lubrificante na cidade de Presidente Prudente - SP. Monografia (Bacharelado em Geografia). Universidade Estadual Paulista, Presidente Prudente/SP, 2013.

Sindirrefino. Produção Industrial/Rerrefino. Disponível em: https://www.sindirrefino.org.br/rerrefino/processo-industrial. Acesso em o6 janeiro de 2021.

TSL Ambiental. Tratamento de solo contaminado com óleo. Disponível em: $\quad$ https://www.tslambiental.com.br/tratamento-solo-contaminado-oleo Acesso em 09 de abril de 2021. 